\title{
Monitoring the quality of e-learning implementation in educational institu- tions
}

\author{
Valerii Habrusiev ${ }^{1, *}$, Hryhoriy Tereshchuk ${ }^{1, * *}$, Ivan Tsidylo $^{1, * * *}$, Serhii Martyniuk ${ }^{1, * * *}$, and Olena Kulyanda $^{2}$ \\ ${ }^{1}$ Ternopil Volodymyr Hnatyuk National Pedagogical University, 2 M. Kryvonosa Str., Ternopil, 46027, Ukraine \\ ${ }^{2}$ Ivan Horbachevsky Ternopil National Medical University, 1 Voli Sq., Ternopil, 46001, Ukraine
}

\begin{abstract}
The article analyzes some aspects of quality control and efficiency of electronic educational and methodological complexes of educational disciplines usage in the educational process. Analysis of the implementation of e-learning and of user work allows to build a model of student's work, identify the disadvantages of both organizational and technological plan and take timely steps to eliminate them. The solution to this problem should include a comprehensive approach to ensure an objective result. Google Analytics tools, Moodle Learning Management System (LMS) tools, the teacher's surveys to monitor the quality of e-learning in an institution proves its efficiency and allows to see the full advantages and disadvantages of ongoing e-learning in an institution, plan and implement further development and improving e-learning. The analysis of the effectiveness of e-courses usage should be carried out in a comprehensive manner, using the monitoring tools of the educational process adopted in the educational institution. Such as surveys for teachers and students, analysis of success, etc. The specifics of e-learning, the Moodle LMS tools and third-party services for collecting statistics and analyzing user activity in the LMS should be taken into account.
\end{abstract}

\section{Introduction}

At the present stage of information society development, the use of information and communication technologies (ICT) contributes to the globalization of education, the development of the international labour market, the growth of various types of personality mobility. An important result of globalization is the improvement of the mobility of students, university entrants and university graduates: a person with a high level of mobility can study, work, cooperate and be competitive in any country. Increase of the academic mobility, the introduction of international norms and standards by which academic qualifications from different countries can be compared and recognized, lead to increased competition among HEIs and improve the quality of higher education [1].

An indispensable condition for social and economic development of any country is investment in education of the population. In this context, the globalization of education contributes to the personal and professional development of professionals.

For Ukraine, informatization of education is extremely relevant in the context of its economic, social and cultural development [2]. The main focus of ICT use is to create an education system focused on the use of the latest ICT in the formation of a well-developed personality, which enables each person to independently acquire knowledge,

\footnotetext{
*e-mail: gabrusev@tnpu.edu.ua

**e-mail: g.tereschuk@tnpu.edu.ua

***e-mail: tsidylo@tnpu.edu.ua

****e-mail: sergmart65@ukr.net
}

skills and competences during education and training [35].

The purpose of the National Strategy for the Development of Education in Ukraine until 2021 is to: update the content, forms, methods and means of learning through the widespread introduction of modern ICT and e-learning in the educational process. The priority of the development of education is the introduction of modern ICT, which ensures the improvement of the educational process, accessibility and effectiveness of education, preparation of the young generation for life in the information society [6].

Introduction of e-learning involves not only the creation of e-courses and the orientation of students to use them during classroom or independent work [7-10], but also control over the effectiveness of the use of created courses in the educational process. Monitoring the implementation of e-learning, the work of users allows you to build a model of student work, identify the shortcomings of both organizational and technological plan and take timely steps to eliminate them. Such monitoring makes it possible to identify morally outdated or unsupported e-learning platforms, to avoid technical problems while users are operating, and to adapt to new software or technical conditions in a timely manner.

\section{Literature review}

The analysis of published research shows the presence of a number of publications on comparisons of learning management systems (LMS) in distance education, in particular with open source. In a study [11] by Cansu Cigdem 
Aydin and Guzin Tirkes, several analyzes and comparisons were conducted on open source LMS. The Moodle system is singled out as one that has many features among other LMS, which are aimed at improving the quality of education and include the tools that an e-learning system should have. In general, the use of open source software will ensure the development of teaching aids and improve the quality of education. Evaluation of usability in Moodle LMS was carried out in the works [9, 12-17]. The convenience of using standard modules in Moodle, one of the leading open source LMS, was evaluated. Thanks to this research, we get significant results and informational advice for administrators, teachers and students on how to improve the effective use of this system [12].

Using learning analytics to predict students' performance in Moodle was revealed in the work by Imani Mwalumbwe and Joel S. Mtebe. Therefore, this study designed and developed Learning Analytics tool and used the tool to determine the causation between LMS usage and students' performance. Data from LMS log of two courses delivered at Mbeya University of Science and Technology were extracted using developed Learning Analytics tool and subjected into linear regression analysis with students' final results. The study found that discussion posts, peer interaction, and exercises were determined to be significant factors for students' academic achievement in blended learning at MUST. Nonetheless, time spend in the LMS, number of downloads, and login frequency were found to have no significant impact on students' learning performance. The implications of these results on improving students' learning are discussed [18].

In the work [19] by I. N. Egorova and O. N. Kadushkevich modern Google Analytics tools have been investigated against effective attraction channels for users and bottlenecks detection. Conducted investigation allowed to suggest modern method for effective usage of Google Analytics tools. The method is based on main traffic indicators analysis, as well as deep analysis of goals and their consecutive tweaking. Method allows to increase website conversion and might be useful for SEO and Web analytics specialists.

T. S. Bondarenko proposes to organize quality monitoring on the basis of a process approach, in which monitoring of the quality of resources is carried out in three directions: the quality of the project, the quality of the process and the quality of the result of their use. In connection with the multidimensional nature of the quality of electronic educational resources, it is proposed to carry out quality assessment based on the use of a hierarchical quality model. At the top level of this model, constructed in accordance with the process approach to management of quality, there are directions of quality monitoring. There are evaluation criteria (didactic quality of the project, methodological quality of the project, etc.) at the next level of the hierarchy of the model. They are used to assess the quality of educational resources. The criteria determine by the indicators, which in turn measure the properties (attributes) of the educational resource. The principal possibilities for measuring of the quality of electronic educational resources in the course of monitor- ing are considered. To evaluate their values the following methods are suggested: measuring, registration, calculation and expert method [20].

Researchers do not pay attention to the possibility of using the distance learning platform and the Google Analytics service in the process of monitoring the quality of e-learning implementation in educational institutions. The purpose of the article is to highlight the capabilities of LMS tools and Google Analytics to monitor the quality of e-learning implementation in the educational process of educational institutions.

\section{Problem solving}

The analysis of the effectiveness of the use of e-courses should be carried out in a comprehensive way using the monitoring tools of the educational process adopted in the educational institution, such as surveys of teachers and students, analysis of progress, etc. The specifics of elearning, the Moodle LMS tools and third-party services for collecting statistics and analyzing user activity in the LMS must be taken into account.

In this article, we will explore the use of the Moodle LMS [21], the Google Analytics Service [22], and a survey of teachers which allows to monitor e-learning.

\subsection{Use of Moodle LMS tools to analyze the use of e-learning}

Taking into account the importance of obtaining data on the operation and use of the learning resource management system, Moodle developers envisaged collecting certain data for further analysis. We shall consider the most commonly used metrics that can be obtained directly from Moodle [3]:

- The most active courses for a given period. A metric for determining the total number of completed actions (page loading, viewing of study material, submitting a task, completing a test) by students and teachers. This parameter is relative and does not allow for objective evaluation of course usage.

- Total report on the most active courses for a given period. This indicator is defined as the average activity of a student or teacher, calculated by:

$$
K=\frac{D}{N c t}
$$

in which $D$ is the total number of course users' actions, $N c t$ is the number of registered users. This parameter allows for a more objective assessment of the activity of using e-courses (figure 1).

- Courses with the highest number of students enrolled for a given period. The student activity rate of a course is calculated as the ratio of the number of active course users to the total number of registered users.

- Courses that lead by the number of views over a given period. The activity rate of students in the use of training resources of the course is calculated as the ratio of 


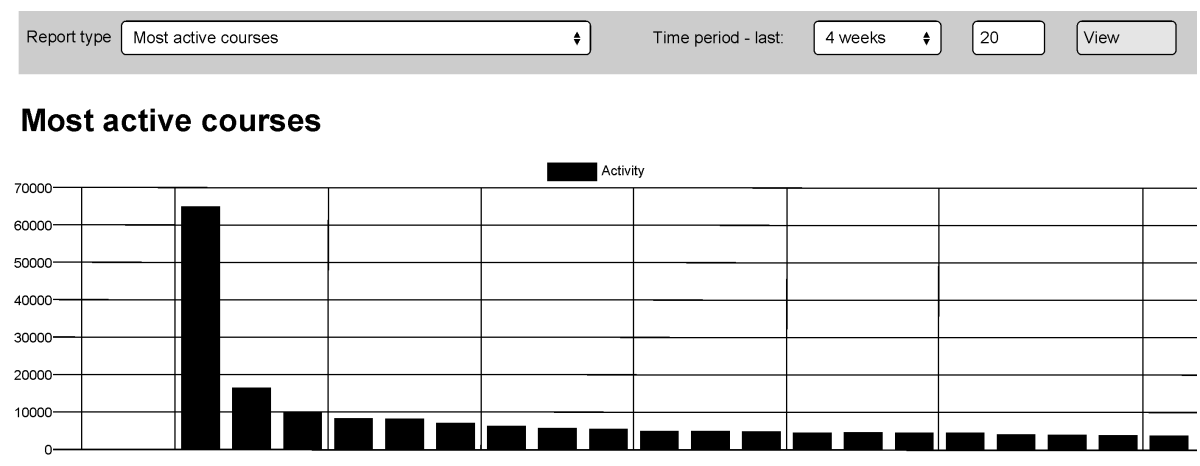

Figure 1. Total report on the most active courses

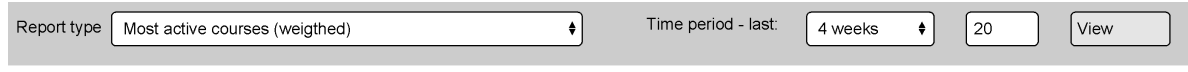

Most active courses (weigthed)

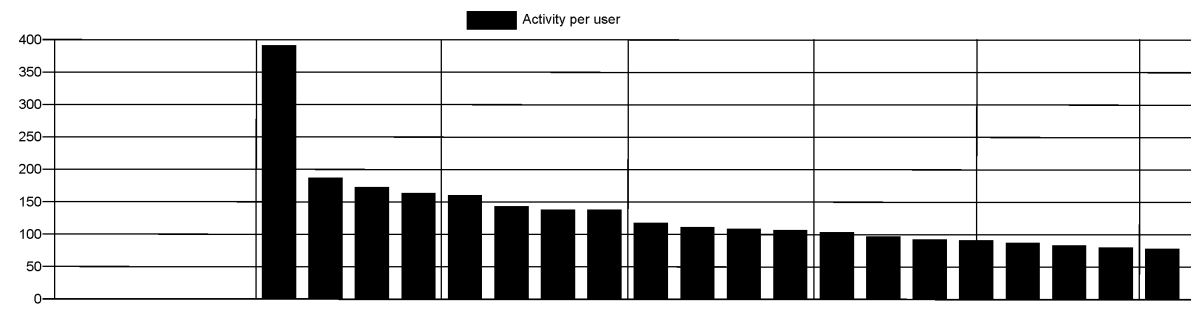

Figure 2. Most active courses, weighted

the total number of views of educational materials to the number of e-mail posts sent or posts in the forum.

- Activity of teachers and students for a given course. This indicator characterizes the activity of students and teachers over a certain period of time. This report allows you to estimate the number of user activities on the system over a given period, both for the system as a whole and for a particular course.

- Event register (activity of students and teachers). Detailed information about the activity of each user of the system allows to determine from which IP address the user worked, what actions they performed on the system, which pages they downloaded. Taking into consideration that the event register only contains information about individual actions of each user, including logging in, page loading, file uploading, etc., further systematization and analysis of this data is a difficult process.

To analyze the effectiveness of e-learning implementation, the most useful are the data on the dynamics of users' work with the e-courses server during a given period and a balanced report on the most active courses over a given period (figure 2).

\subsection{Using Google Analytics tools to analyze the use of e-learning}

Interpreting Google Analytics data from e-learning sites may be slightly different from the commonly accepted interpretation of data for business or social networking sites and Moodle LMS due to the specific features and organization of e-learning users. The main feature is that the number of potential users is known beforehand, this is the entire contingent of students studying at the institution or a separate group or stream. The purpose of the analysis is not to identify the problematic places why the client left and did not return for the second time or did not perform certain actions in the system [4, 20, 23], but to analyze how students and teachers use e-courses.

We ought to consider the main metrics that can be used to analyze the effectiveness of e-learning [21].

- Referral sources. The address of the page from which the user connected to the current page and data allow you to determine how the user got to the page. Additional information can be obtained from the address of the previous page: for example, a keyword that a user entered on a search engine and then saw a link to the e-courses site. This information is used to segment, analyze traffic sources, determine how students access the e-courses server, evaluate the demand of outsiders for distance learning services, etc.

- The page address the user was visiting (page views). Page visit information. This data allows you to determine which pages you visit most often, to determine in more detail what students do on the system, such as taking tests, viewing or downloading training materials, downloading system tasks, etc.

- Exact request time. The time users visit pages is saved. Query time information lets you determine what time 


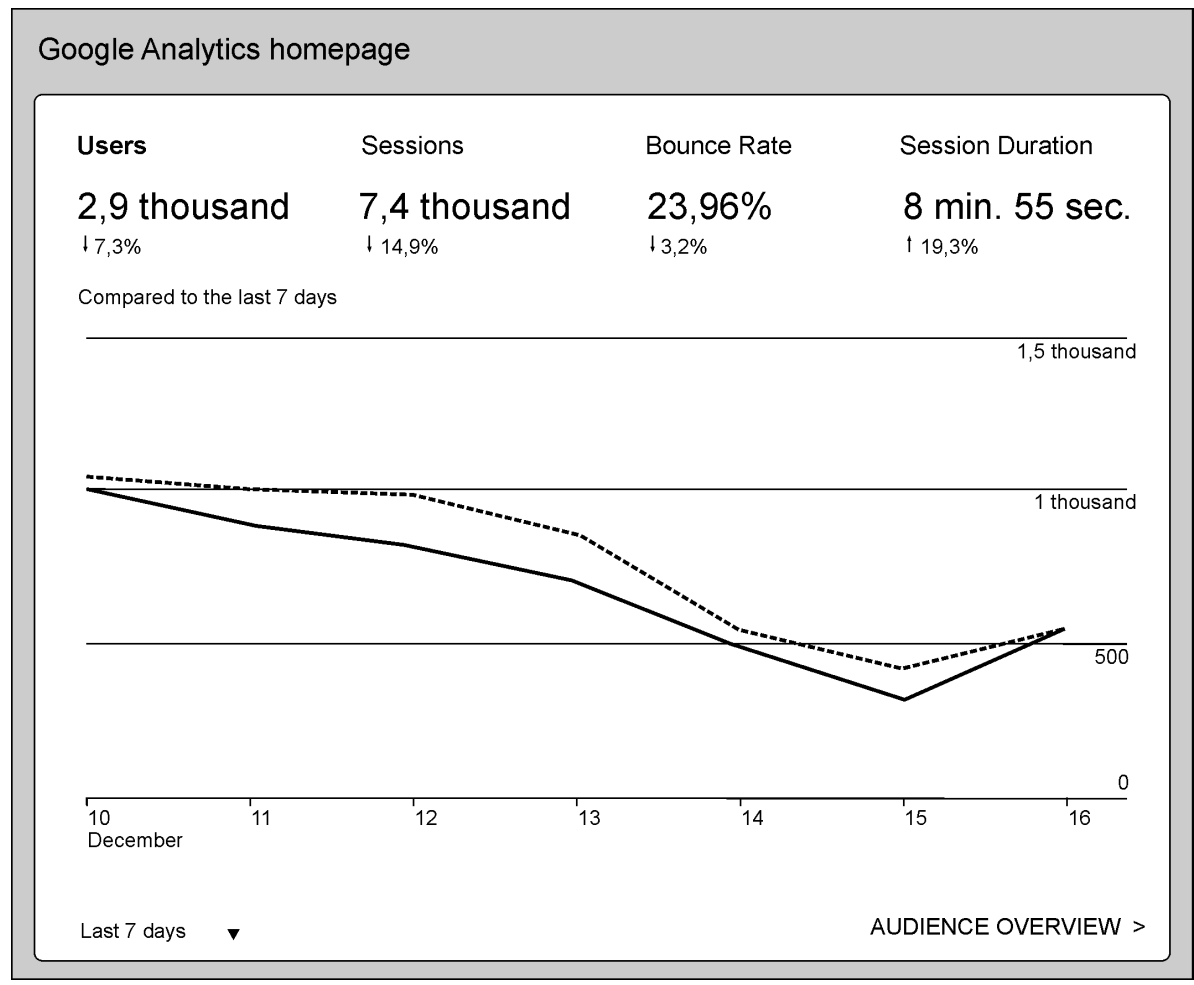

Figure 3. General information about using e-courses in Google Analytics

students are most active in e-courses, and schedule time for online events, such as webinars.

- Average page view time. Determining the average browsing time by page users. This parameter is relative, but it allows on average of how much time students use e-courses to prepare for classes, submit completed tasks, and perform in tests.

- Bounce rate. It determines the percentage of users who have started browsing the site from this page and have not gone to another site but immediately closed the site. This is the number of visitors (usually a percentage of total) who have visited only one page on the site (figure 3).

The bounce rate for e-learning sites is no longer as critical a parameter as for other types of sites because the number of site users is fixed and known in advance. This parameter should be considered depending on the situation:

1) bounce rate for the homepage;

2) bounce rate for the courses page;

3) bounce rate for the learning resources page (test, task, hyperlink, etc.).

The actual setting allows you to estimate how many students have viewed this page and then left the system. In each case, the interpretation will be different.

- Daily activity of students. Information about the hourly activity of e-learning users during the day. The analysis of these data allows teachers to plan their time for conducting online activities, especially when conducting distance learning (figure 4).

Therefore, it can be concluded, based on the dynamics of student activity, that e-courses are used for independent student work. Visitors (unique visitors, visitors, users, reach). The statistics system analyzes all the pageviews it records and tries to determine which ones were made from a single browser. Summing up the number of different browsers over a period of time, it counts the number of unique visitors, "meaning that one browser is used by one user. Google Analytics determines the "uniqueness" of a visitor by leaving a unique number of cookies on their browser during the first visit. All visits by this user will now be combined with this ID. With this metric, they can estimate the average number of students and teachers who use e-courses for the selected period.

- Website presence time. A metric that contains information about the amount of time a user has spent on the site. However, since the statistics system logs only the time the page is opened, it is not possible to determine the time the user spent on the last of the pages opened. Therefore, it is not possible to determine an average view time for users who have only one page. It is also impossible to estimate how long a user actually worked with the page and how much time it was opened in the background in the next window. Despite the relativity of this metric, some conclusions can be drawn about the work of students with e-courses.

- User settings. The statistics system determines which browser the client has, the type of operating system, 


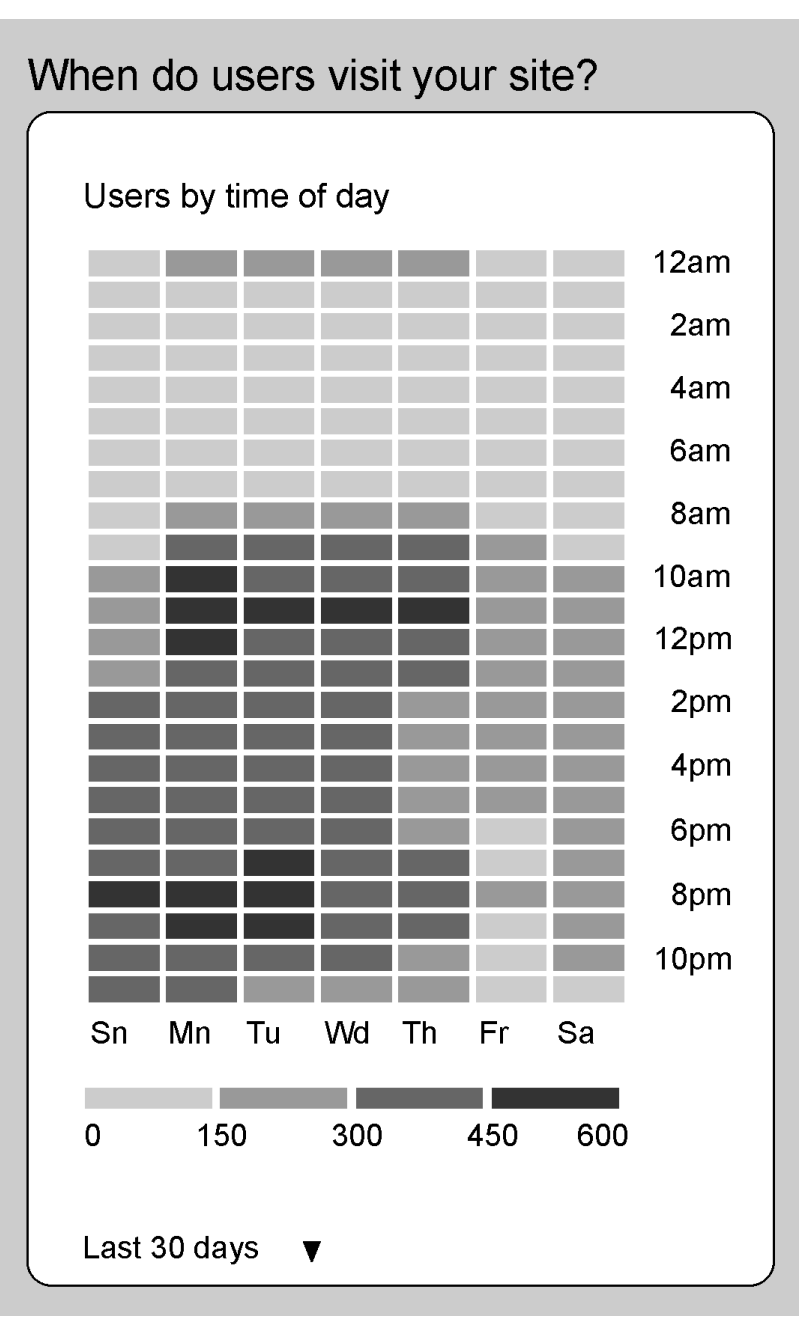

Figure 4. Daily activity of students

monitor resolution, etc. The results of the analysis of the equipment used by users for working with e-courses indicate that students are beginning to use mobile platforms (figure 5).

It should also be noted that with the trend of proliferation of tablets, smartphones, the number of users who use mobile technologies will only increase. This tendency must be taken into account during the development of ecourses and during the planned upgrades of the e-learning system software component.

\subsection{Teachers survey to further analyze the use of e-learning}

The survey is one of the most common methods of obtaining information about respondents. The survey was developed and conducted by the TNPU Distance Learning Center, author Valerii Habrusiev [24]. More than 200 teachers were involved in the survey, the survey is to ask people specific questions that answer the researcher to obtain the necessary information, depending on the tasks of the study. The characteristics of the survey can be attributed to its mass, which is caused by the specifics of the tasks

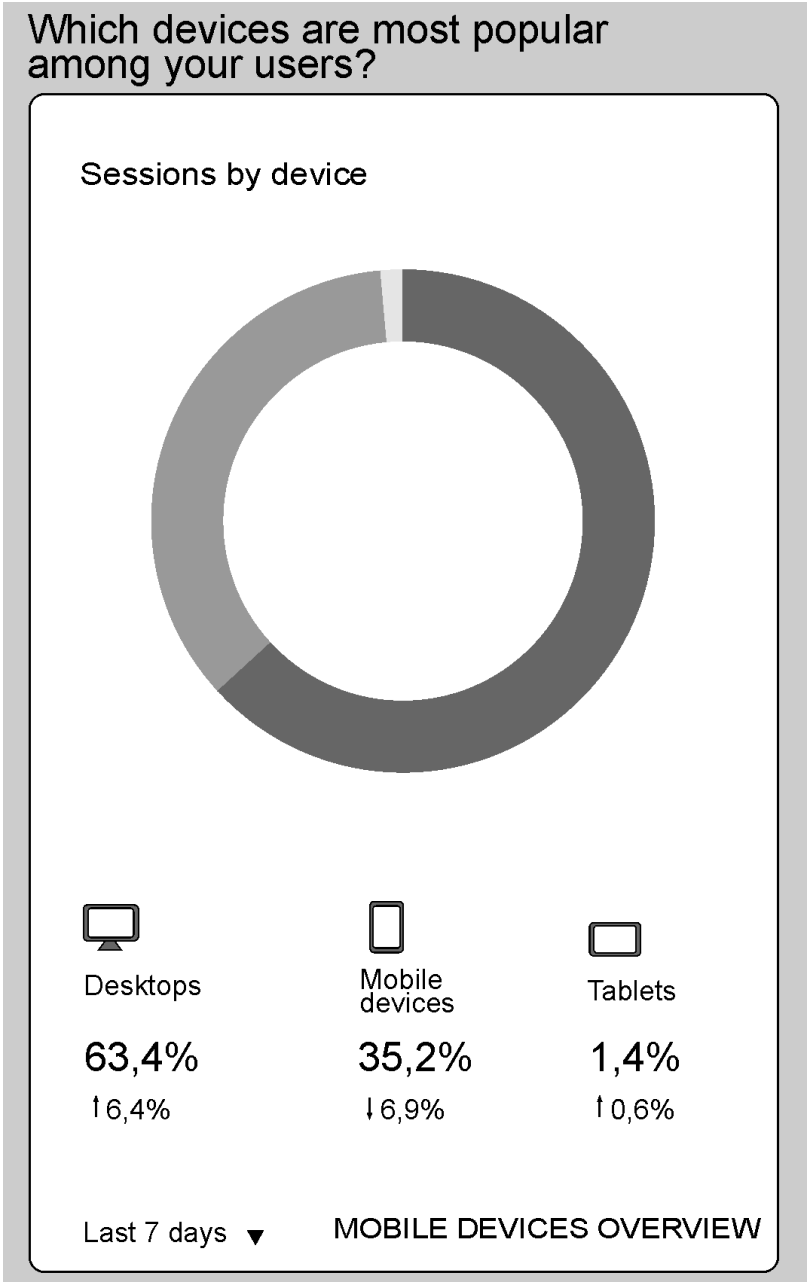

Figure 5. Devices used by users to work with e-courses

that they solve. In pedagogical, sociological research, it is advisable to conduct a survey by means of a questionnaire.

Questionnaire is a method of obtaining information through the written answers of the respondents to the system of standardized questions of pre-prepared questionnaires. By generalizing the completed questionnaires objective information about the attitude of teachers to e-learning is obtained, problems of the implemented elearning model are identified. The information obtained can be used in the development of new training programs, the choice of teaching methods, ways of presenting information during the implementation of e-learning.

During the evaluation of the e-learning conducted, a survey was conducted among university professors to find out information about the forms of the educational process during the use of e-courses, the number of students who use the e-courses etc.

1. How many students use your online courses?

- less than $25-5.1 \%$;

- $25-100-12.8 \%$;

- $100-150-30.8 \%$;

- 150-200-25.6\%;

- more than $200-25.6 \%$; 
2. Choose the option for students to use the e-courses you have developed:

- classroom work - $15.4 \%$;

- independent work - 53.8\%;

- individual work - $28.2 \%$;

- do not use - 7.7\%;

3. Rate on a 3 point scale your level of e-learning use:

- low level-33.3\%;

- average level - 51.3\%;

- high level - 15.4\%;

4. How do you assess the level of readiness of the university for the introduction of mixed (inverted) courses, mass online courses.

- low - 30.8\%

- average $-51.3 \%$;

- high - $17.9 \%$;

5. What, in your opinion, is the most important thing to do in order to implement mixed (inverted) online mass courses?

- to improve regulatory support $-20.5 \%$;

- to improve methodological support for e-learning $-30.8 \%$;

- to reduce the number of hours of classroom work $-23.1 \%$

- to improve the material and technical base of the used equipment $-25.6 \%$;

- none of the above $-2.6 \%$;

6. Choose the form of e-learning you use to work with students.

- traditional (classroom work only) - 17.9\%;

- mass online courses $-2.6 \%$;

- mixed learning - 84.6\%;

- inverted education $-5.1 \%$;

- none of the above $-0 \%$;

7. How do you evaluate your level of readiness for the implementation of mixed (inverted) training, mass online courses, distance learning.

- low - 41\%;

- average $-46.2 \%$;

- high - $12.8 \%$;

The results of the survey indicate that e-learning (ecourses) is used mainly to provide independent $(53.8 \%)$ and individual work $(28.2 \%)$ students. The identified problems mainly relate to the e-learning regulatory framework $(56.4 \%)$ and the methodological training of teachers, which is also confirmed by the poor use of e-learning potential $(51.3 \%)$.

\section{Conclusions}

Taking into account the increasing attention to e-learning technologies and their introduction into the educational process of educational institutions at all levels of accreditation, it can be stated that the quality control of e-learning, the development of methods and appropriate tools for such monitoring will be a constant focus of education methodologists and managers. The solution of this problem should include a comprehensive approach to ensure an objective result.

Using Google Analytics tools, Moodle LMS tools, surveying teachers to monitor e-learning quality in an educational setting proves effective and allows you to see all the benefits and disadvantages of ongoing e-learning in an educational setting, plan and implement further development and improvement of e-learning, allows to build in the future the model of work of the student, to reveal shortcomings of both organizational and technical planning and to take timely action to address them. Such monitoring makes it possible to identify morally outdated or unsupported e-learning platforms, to avoid technical problems while users are operating, and to adapt to new software or technical conditions in a timely manner.

Taking into consideration the increasing attention to e-learning technologies and their introduction into the educational process of educational institutions at all levels of accreditation, it can be stated that the issues of quality control of e-learning, the development of methods and appropriate tools for such control will constantly be the focus of methodologists and managers in the field of education. The solution to this problem should include a comprehensive approach to ensure an objective result.

Using Google Analytics tools, Moodle LMS tools, surveying university lecturers to monitor the quality of elearning at educational establishments proves effective and allows them to see all the benefits and disadvantages of ongoing e-learning in the institution, plan and implement further development and improvement of e-learning.

The analysis of the effectiveness of the use of e-courses should be carried out in a comprehensive way using the monitoring tools of the educational process adopted in the educational institution, such as surveys of teachers and students, analysis of success, etc. The specifics of elearning, the Moodle LMS tools and third-party services for collecting statistics and analyzing user activity in the LMS must be taken into account.

Analysis of the implementation of e-learning and of user work allows to build a model of student's work, identify the disadvantages of both organizational and technological plan and take timely steps to eliminate them.

\section{References}

[1] M.I. Striuk, S.O. Semerikov, A.M. Striuk, Information Technologies and Learning Tools 49, 37 (2015)

[2] E. Fedorenko, V. Velychko, A. Stopkin, A. Chorna, V. Soloviev, CEUR Workshop Proceedings 2433, 20 (2019) 
[3] V. Habrusev, H. Tereshchuk, MOODLE Learning Resources Management System (TNPU after V. Hnatiuk, Ternopil, 2011)

[4] A. Kaushik, Web Analytics 2.0: The Art of Online Accountability and Science of Customer Centricity (Sybex, 2009)

[5] S.O. Semerikov, I.O. Teplytskyi, V.N. Soloviev, V.A. Hamaniuk, N.S. Ponomareva, O.H. Kolgatin, L.S. Kolgatina, T.V. Byelyavtseva, S.M. Amelina, R.O. Tarasenko, Journal of Physics: Conference Series 1840, 012036 (2021)

[6] National Strategy for the Development of Education in Ukraine until 2021 (2013), https: //zakon. rada.gov.ua/laws/show/344/2013\#Text

[7] V. Habrusev, H. Tereshchuk, Regulations on the electronic educational-methodical complex of the discipline (TNPU after V. Hnatiuk, Ternopil, 2014)

[8] O. Lavrentieva, L. Rybalko, O. Tsys, A. Uchitel, CEUR Workshop Proceedings 2433, 102 (2019)

[9] V. Ustinova, S. Shokaliuk, I. Mintii, A. Pikilnyak, CEUR Workshop Proceedings 2433, 308 (2019)

[10] V. Tkachuk, Y. Yechkalo, S. Semerikov, M. Kislova, V. Khotskina, CEUR Workshop Proceedings 2732, 1217 (2020)

[11] C.C. Aydin, G. Tirkes, Open source learning management systems in e-learning and Moodle, in IEEE EDUCON 2010 Conference (2010), pp. 593-600

[12] G. Kakasevski, M. Mihajlov, S. Arsenovski, S. Chungurski, Evaluating usability in learning management system moodle, in ITI 2008 - 30th International Conference on Information Technology Inter- faces (2008), pp. 613-618

[13] P. Nechypurenko, S. Semerikov, CEUR Workshop Proceedings 1844, 319 (2017)

[14] I. Mintii, S. Shokaliuk, T. Vakaliuk, M. Mintii, V. Soloviev, CEUR Workshop Proceedings 2433, 529 (2019)

[15] I. Mintii, CEUR Workshop Proceedings 2643, 293 (2020)

[16] A. Abdula, H. Baluta, N. Kozachenko, D. Kassim, CEUR Workshop Proceedings 2643, 306 (2020)

[17] K. Polhun, T. Kramarenko, M. Maloivan, A. Tomilina, Journal of Physics: Conference Series 1840, 012053 (2021)

[18] I. Mwalumbwe, J.S. Mtebe, The Electronic Journal of Information Systems in Developing Countries 79, 1 (2017)

[19] I.N. Egorova, O.N. Kadushkevich, ScienceRise 1, 40-44 (2016)

[20] T.S. Bondarenko, Problems of engineering and pedagogical education pp. 32-44 (2016)

[21] Moodle - Open-source learning platform (2021), http://www . moodle.org

[22] Google analytics (2020), https://wwW.google. com/analytics

[23] On the basic principles of development of information society in Ukraine for 2007-2015 (2007), https://zakon.rada.gov.ua/laws/show/ 537-16\#Text

[24] TNPU questionnaire, accessed 2020, 11 Nov, https://https://forms.gle/ RJ2RVZYpu7BEuBBK9/ 